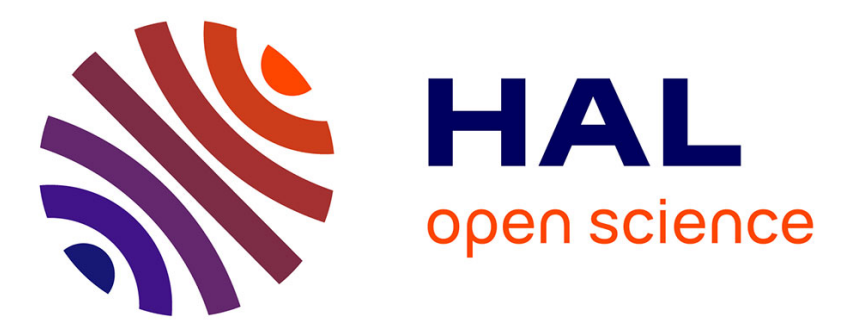

\title{
Macroeconomic expectations and time varying heterogeneity: Evidence from individual survey data
}

Imane El Ouadghiri, Remzi Uctum

\section{To cite this version:}

Imane El Ouadghiri, Remzi Uctum. Macroeconomic expectations and time varying heterogeneity: Evidence from individual survey data. Applied Economics, 2020, 52 (23), pp.2443-2459. 10.1080/00036846.2019.1691713 . hal-03319091

\section{HAL Id: hal-03319091 \\ https://hal.science/hal-03319091}

Submitted on 11 Aug 2021

HAL is a multi-disciplinary open access archive for the deposit and dissemination of scientific research documents, whether they are published or not. The documents may come from teaching and research institutions in France or abroad, or from public or private research centers.
L'archive ouverte pluridisciplinaire HAL, est destinée au dépôt et à la diffusion de documents scientifiques de niveau recherche, publiés ou non, émanant des établissements d'enseignement et de recherche français ou étrangers, des laboratoires publics ou privés. 


\title{
Macroeconomic expectations and time varying heterogeneity: Evidence from individual survey data
}

\author{
Imane El Ouadghiri* Remzi Uctum ${ }^{\dagger}$
}

\begin{abstract}
The goal of this paper is to investigate forecast heterogeneity and time variability in the formation of expectations using disaggregated monthly survey data on macroeconomic indicators provided by Bloomberg from June 1998 to August 2017. We show that our panel of forecasters are not rational and are moderately heterogeneous and thus confirm that previously well-established results on asset prices hold for macroeconomic indicators. The estimation of our flexible hybrid forecast model - defined at any time as a combination of the extrapolative, regressive, adaptive and interactive heuristics - using the Bai and Perron (1998) methodology reveals a significant timedependence in the structural model with some inertia in extrapolative and adaptive profiles. Changes in the formation of expectations are triggered mostly by financial shocks, and uncertainty is dealt with by using complex processes in which the fundamentalist component overweighs chartist activity. Forecasters whose models combine different relevant rules and display high temporal flexibility provide the most accurate forecasts. Authorities can then stabilize the domestic markets by encouraging fundamentalists' forecasts through increased transparency policy.
\end{abstract}

JEL Classification: C32, C52, D84, E71.

Keywords: dynamic heterogeneity, flexible forecast model, formation of expectations, individual survey data, macroeconomic indicators.

* Léonard de Vinci Pôle Universitaire, Research Center, 92916 Paris La Défense, France and EconomiX, Université Paris Nanterre, France. E-mail: imane.el_ouadghiri@devinci.fr.

${ }^{\dagger}$ EconomiX, Centre National de la Recherche Scientifique and Université Paris Nanterre, France.

E-mail: uctum@parisnanterre.fr. Corresponding author. 


\section{Introduction}

The recent financial crises demonstrated the inability of institutional and private forecasters to predict the warning signs of the turmoil episodes as well as their severity. Relatedly, a widespread empirical literature using survey-based measures of expectations in various asset markets (exchange rates, interest rates, stock prices and oil prices) reports that asset price expectations are not rational. The question of how they are formed is addressed, among a variety of approaches, by exploring in what extent standard forecast rules, ${ }^{1}$ possibly augmented by other expected fundamentals, explains experts' expectations. In addition, differences in economic agents' ability to collect and analyze relevant information support the assumption that their expectations are heterogeneous (Branch, 2004; Kirman, 2006; Hommes, 2006). Using individual macroeconomic survey data from Bloomberg, we contribute to the literature on expectation formation by examining how experts modify their forecast strategies over time in response to endogenous changes in their economic environment, such as alternating periods of stability and crisis. This approach is innovative in that it allows us to investigate several issues related to the time-varying heterogeneity of expectation behavior, e.g., whether all forecasters are sensitive to the same major structural shocks, how and why financial crises trigger changes in forecasting models, and the extent to which this temporal flexibility in expectation formation enhances forecast performance.

There is an extensive literature which challenges the rational expectations hypothesis $(\mathrm{REH})$ by relaxing the postulate that agents use full information in forming their expectations. Two main factors driving departures from REH are highlighted: information costs and limited cognitive ability of agents to collect and process information. One major approach pertaining to the first category is the sticky information model (Mankiw and Reis, 2002), according to which agents update their forecast infrequently because of the costs of acquiring or processing information, so that expectations are not based on the most recent information. The role of information costs in expectation formation mechanism was already emphasized by the theory of economically rational expectations introduced by Feige and Pearce (1976). According to this theory, at the equilibrium, agents collect and process information until the unit cost of information they face relative to their aversion to making forecast errors equals the marginal gain achieved by a decrease in the forecast error due to the additional information. It then results that low (high) information cost and high (low) aversion to misestimation motivate the use of a large (little) amount of information collected. Hence, because of the cost of information, it may be rational for agents to adopt a less expensive forecasting strategy, even though doing so they must accept a higher amount of forecast error. Branch (2004) reaches the same conclusion in that because of costs, agents rationally choose methods other than the most accurate one, which leads them to rationally form heterogeneous expectations. The second category of approaches to deviations from REH include primarily the rational inattention theory,

\footnotetext{
${ }^{1}$ These are the extrapolative (bandwagon), adaptive (error-correcting) and regressive (mean-reverting) rules which assume that forecast assessment is based upon past trends in the variable of interest, past forecast errors and the spread between the actual and target values of the variable, respectively.
} 
based on the idea that agents have limited capacity for processing information and must therefore choose which information to prioritize (Sims, 2003). Sharing the same spirit is the "sparse-max" model proposed by Gabaix (2014), where bounded rational agents build a simplified but tractable model of the economy which is purposefully based on variables of first-order importance. An alternative approach is the noisy information model, where agents perceive information with imperfect precision due to their limited capacity to pay attention to all information available (Woodford, 2002). The idea of relying on a restricted set of information in order to simplify complex tasks dates back to Tversky and Kahneman (1974), who have shown experimentally that in forming predictions, individuals rely on basic judgmental decision strategies (heuristics) by anchoring the prediction on a benchmark made by the recent past or easily observable values (the anchor), before they adjust this information to reach an acceptable value. The survey-based limited information models that are considered in this paper are consistent with the economically rational expectations framework and can be viewed as reflecting the forecast anchoring behavior with an anchor extended to some elaborate benchmark, in line with Hess and Orbe (2013).

All these survey-based models are assumed to be stable over time, i.e., that the weights and the structural coefficients implicitly contained in the slope parameters associated with the rules are time-invariant. However, the empirical literature on boundedly rational heterogeneous agent models provides strong evidence that the weights associated with rules change over time. In line with Brock and Hommes (1997, 1998), some authors show that heterogeneity in exchange rate expectations follows an evolutionary dynamic, in that agents switch between extrapolative and regressive rules - and thus alternate between chartist and fundamentalist activities, respectively - according to the relative profitability of these mechanisms (see among others, De Grauwe and Grimaldi, 2006; models augmented by a carry trade component based on interest differentials between countries are proposed by Jongen et al., 2012; ter Ellen et al., 2013; Spronk and Zwinkels, 2013). Yet another strand of studies argues that, because of shifts in agents' behavior, institutional reforms, policy changes, or cycle reversals, the structural parameters associated with different fundamentals in macroeconomic and financial series are time varying (Cogley and Sargent, 2005; Sims and Zha, 2006; Canova, 2009) or subject to structural breaks (Ireland, 2001; Fernald, 2007; Inoue and Rossi, 2011), implying that the actual law of motion agents' expectations are based on is unstable. These findings strongly suggest that when modeling expectations, slope parameters associated with the explanatory components should be allowed to vary over time. Note that forecasters' reliance on mixed forecast models with time-dependent parameters can still be given a theoretical insight within the economically rational expectations framework provided that information costs faced by agents and their aversion to misforecast are allowed to be time-varying. ${ }^{2}$

The literature on expectation formation using survey data overwhelmingly focuses on prices in financial markets or inflation. Studies attempting at investigating the formation of expectations of macroeconomic variables other than inflation are very scarce. We

\footnotetext{
${ }^{2}$ These are realistic assumptions since the soar of information systems reduce costs and aversion to making forecast errors is sensitive to the state of the economy.
} 
consider three important macroeconomic indicators that are closely scrutinized and regularly forecasted by analysts in Bloomberg surveys: the unemployment rate, new home sales and the consumer confidence index. Employment is perhaps the primary indicator of economic welfare, far before consumer and producer price indices. Information on new home sales is also a key signal for market participants, especially for detecting ongoing economic inflection points. Changes in consumer confidence index are viewed by financial markets as a barometer of the economic climate, which helps in predicting the near future by providing insight about the direction of the economy.

We allow forecasters to rely upon flexible combinations of the traditional extrapolative, regressive and adaptive rules to which we add an interactive rule, which accounts for the discrepancies between the past individual and market forecasts. For each agent and each variable to be forecasted, we examine their forecast behavior over time by estimating our mixed model using Bai an Perron's (1998, 2003) method with endogenous structural breaks. Because the number and locations of breaks are both estimated endogenously, i.e., determined by the data, we ascertain that an optimal parameter change pattern is depicted for each forecaster as their behavior evolves over time. Thus, by estimating the model with unknown structural breaks, we represent more accurately the behavior of each forecaster. Ignoring these breaks when they are present in the relationship tested would lead to inconsistent estimates. Our approach emphasizes discrete changes in the forecast model, instead of continuous changes represented by a time-varying parameter model. The rationale for our choice is that a professional forecaster is not likely to change their forecast model continuously by monitoring all types of economic shocks, and will probably ignore those of little practical importance to the market under observation. Only major events matter and lead the forecaster to adapt their expectation behavior to the new environment. In this case, revisions are undertaken immediately by the agent once they fully integrate the piece of relevant information, hence our discrete change assumption. To the best of our knowledge, no previous study has examined the evolutionary aspect of individual forecast strategies in response to crises, changes in policy stances or idiosyncratic events.

The estimation of our individual forecast models leads to five main findings. First, we confirm for our macroeconomic indicators the well documented results in the empirical literature that the rational expectation hypothesis is rejected and show the relevance of the standard extrapolative, regressive, adaptive, but also interactive rules. Second, a high degree of instability characterizes the impacts of expectation schemes and often the structure of the forecasting model itself. In this model that evolves over time, the most stable strategies seem to be the ones consisting in extrapolating from past trends and learning from past errors, which interestingly are the least costly information-based processes. Third, changes in the expectation formation mostly occur as a response to economic or financial shocks and, to a smaller extent, to idiosyncratic motives. Sophisticated forecast models based on a diversity of information are triggered by financial crises. Fourth, periods of economic crises lead agents to become less chartist and more fundamentalist in predicting the unemployment rate. Fifth, forecasters who use hybrid expectation models 
and display high temporal flexibility in revising their processes provide the most accurate forecasts.

The paper is organized as follows. In section 2, we present the heuristics that each forecaster combines at any time in their own way to form their expectations. Section 3 outlines the Bloomberg survey data used. In section 4 we discuss the hypotheses of heterogeneity and of rationality of the individual responses to the survey, then we present the estimation results of our flexible forecast model for each forecaster, and finally we identify which models provide the most accurate forecasts. Section 5 concludes.

\section{The flexible mixed forecast model}

We now present the different forecast rules and the mixed model. Let $a_{t}=\left\{h_{t} ; s_{t} ; u_{t}\right\}$ be the generic notation of the log of new home sales $\left(h_{t}\right)$, the log of the consumer confidence index $\left(s_{t}\right)$, and the unemployment rate $\left(u_{t}\right)$. An agent $i$ is assumed to compute their expected change in the macroeconomic indicator $E_{t}^{i} a_{t+1}-a_{t}$ using a time-dependent combination of different heuristics. ${ }^{3}$ To simplify notations, we omit rule-specifying symbols from parameters.

The extrapolative rule is defined as a moving average (of order $k_{i}$ ) of the current and past monthly observed values:

$$
E_{t}^{i} a_{t+1}-a_{t}=\alpha_{i 0}+\alpha_{i 1} \frac{1}{k_{i}+1} \sum_{j=0}^{k_{i}}\left(a_{t-j}-a_{t-j-1}\right)
$$

where the optimal value of $k_{i}$ for each agent $i$ is determined in the course of the estimation process. Eq. (1) says that the forecast is calculated as a projection of actual or past trends. Although the theoretical sign of $\alpha_{i 1}$ is generally positive (bandwagon effect), a negative value is possible as it can reflect a naive mean-reverting process (systemic turning tendency in the forecast direction with respect to the observed change), also called contrarian expectations. Expectations are destabilizing in the former case and stabilizing in the latter case.

The regressive rule states that the expected indicator depends on the spread between a long-term target value $\bar{a}_{t}$ and the actual value $a_{t}$ :

$$
E_{t}^{i} a_{t+1}-a_{t}=\gamma_{i 0}+\gamma_{i 1}\left(\bar{a}_{t}-a_{t}\right)
$$

\footnotetext{
${ }^{3}$ Our emphasis on modeling changes in expectations instead of levels is in line with Pesaran et al. (1985), who show that subjective sociological factors durably affect expectations in levels but the influence is considerably reduced when expected changes are considered.
} 
where $\bar{a}_{t}$ is supposed to depend upon macroeconomic fundamentals that we specify later. ${ }^{4}$ The standard regressive forecasting rule implies $0<\gamma_{i 1}<1$ : a positive (negative) spread drives positive (negative) changes in extrapolative expectations, which then are stabilizing. However, we allow negative values of $\gamma_{i 1}$ to account for the case in which an agent believes that the macroeconomic indicator will not be mean-reverting and that the observed discrepancy between the indicator and its target will keep widening in the same direction. This characterizes an explosive and destabilizing expectation process, after which beliefs can be reversed.

According to the adaptive rule, expected changes are proportional to the last observable forecast error:

$$
E_{t}^{i} a_{t+1}-a_{t}=\beta_{i 0}+\beta_{i 1}\left(E_{t-1}^{i} a_{t}-a_{t}\right)
$$

where $0<\beta_{i 1}<1$.

As we are concerned with individual forecasters, we consider an additional rule, according to which the forecaster $i$ positions their current opinion with respect to those of the other forecasters by observing the past average forecast revealed by the survey. We call this behavior the interactive rule ${ }^{5}$ and write it as follows:

$$
E_{t}^{i} a_{t+1}-a_{t}=\delta_{i 0}+\delta_{i 1} \frac{1}{k_{i}} \sum_{j=1}^{k_{i}}\left(E_{t-j}^{M} a_{t-j+1}-E_{t-j}^{i} a_{t-j+1}\right)
$$

where we measure $E_{t-j}^{M} a_{t-j+1}$ using the median forecast and determine the moving average optimal value $k_{i}$ in the course of the estimation. Eq. (4) says that the agent cares not to deviate too much and on average from the market's opinion if he has mimetic behavior, in which case $0<\delta_{i 1}<1$. On the contrary, the agent can go against the consensus $\left(\delta_{i 1}<0\right)$ if they disagree with the market opinion or if their goal is to create a publicity effect even though their revealed response does not reflect their opinion. These two opposite attitudes are consistent with Haltiwanger and Waldman $(1985,1989)$, who refer to them as "strategic complements" and "strategic substitutes," respectively.

Note that each of these heuristics collapses to the special case of naive expectations when all the parameters of the heuristic are zero (too costly information or neutrality to forecast errors). The agent's forecast is then simply equal to the value actually observed. Because the individual cost of information and, perhaps to a lesser extent, the individ-

\footnotetext{
${ }^{4}$ Note that each agent $i$ has in mind their own perception of the target, say $\bar{a}_{t}^{i}$, which can be different from the true fundamentals-based target $\bar{a}_{t}$. Let $\bar{a}_{t}^{i}=\bar{a}_{t}+\omega_{0}^{i}+\eta_{t}^{i}$ where $\omega_{0}^{i}$ is a systematic bias and $\eta_{t}^{i}$ the stochastic deviation of $\bar{a}_{t}^{i}$ from $\bar{a}_{t}\left(\eta_{t}^{i}\right.$ may contain fundamentals that are omitted in $\bar{a}_{t}^{i}$ or absorb any mismeasurement of their impact). Using the subjective target $\bar{a}_{t}^{i}$ into Eq. (2) in place of the true target still amounts to specifying the regressive component with the true target $\bar{a}_{t}$ as in Eq. (2), $\omega_{0}^{i}$ and $\eta_{t}^{i}$ then being captured by the intercept and the error term of the econometric expectation model. Misspecification in the subjective target would lead to autocorrelated residuals in the model, whereas good fits from this model would imply a correct assessment of the true target by the agent.

${ }^{5}$ Flieth and Foster (2002) use the term "interactive process" in the sense that decision-makers communicate with each other to exchange their opinions so that their expectations are directly influenced by the amount of information shared. Instead, we believe that market participants do not find the opportunity of communicating directly but endeavor to guess others' average opinion through the past average forecast released by the survey. Acting this way, each agent indirectly interacts with the market because all others' contributions to the past average forecast influence agent's current forecast.
} 
ual aversion to making forecast errors are time-varying, the determination of the optimal amount of information sketched above is reiterated at each point in time, implying that the forecast model may be revised from one period to another. For example, when there is uncertainty about the fundamental value of a variable of interest, it will be more costly for a fundamentalist investor to find relevant information revealing the true fundamental value, so that they will have an incentive to switch their forecast strategy toward, say, chartist activity. More generally, when the environment changes, market participants adjust their information set to make the best possible forecast consistent with their actual cost/aversion ratio. This leads to a change in the parameters of the expectation model, or even to an expansion of the model to new components or to a contraction of it. The flexible mixed forecast model can be represented using the following combination of the four heuristics (1) to (4) with time-varying weights:

$$
\begin{gathered}
E_{t}^{i} a_{t+1}-a_{t}=\theta_{0 t}^{i}+\theta_{1 t}^{i} \mathrm{MA}_{j}^{i}\left(a_{t-j}-a_{t-j-1}\right)+\theta_{2 t}^{i}\left(E_{t-1}^{i} a_{t}-a_{t}\right)+\theta_{3 t}^{i}\left(\bar{a}_{t}-a_{t}\right) \\
+\theta_{4 t}^{i} \mathrm{MA}_{j}^{i}\left(E_{t-j}^{M} a_{t-j+1}-E_{t-j}^{i} a_{t-j+1}\right)
\end{gathered}
$$

where $\mathrm{MA}_{j}^{i}$ stands for the moving averages defined in Eqs.(1) and (4). Note that the slope parameters do not sum to 1 at any time because they are defined as products of weighting coefficients (which do sum to 1) and structural parameters.

\section{The data}

In this paper, we use monthly individual surveys of professional experts' one-month horizon expectations on future values of three major US macroeconomic indicators provided by Bloomberg: the unemployment rate (UR, in percent), new home sales (NHS, in thousands of units) and the consumer confidence index (CCI, in index level). ${ }^{6}$ Perhaps the primary indicator of the health of the economy is employment. Released early in the month by the US Bureau of Labor Statistics, it reveals, beyond the situation in the labor market, information about income, production, and interest rates and directly influences many other economic indicators. Further, it is used as a threshold criterion by the Federal Reserve for making changes in monetary policy. We thus make the unemployment rate one of our variables of interest. Reports on new home sales are released at the end of the month by the US Bureau of the Census and reflect housing market trends, which are strongly related to economic well-being. Analysts are particularly interested in following new home sales as these are early warning signs of recessions; this indicator has indeed a strong tendency to fall one or two years before the beginning of economic downturns in the United States, as it systemically did before recessions in December 1969 - November 1970, November 1973 - March 1975, January - July 1980, July 1981 - November 1982, July 1990

\footnotetext{
${ }^{6}$ Note that for many macroeconomic indicators, the announcement release is scheduled at a date after the end of the reference period. New home sales and unemployment rate are typically released in the second half of the month following the reference month and on the first Friday after the reference month, respectively. Even though Bloomberg allows forecasters to update their forecasts up to the week preceding the announcement release, our choice of focusing on one-month ahead forecasts (with respect to the scheduled announcement dates) ensures that these are made within the reference month.
} 
- March 1991, March - November 2001, and December 2007 - June 2009, as determined by the NBER. The consumer confidence index is based on consumers' perceptions about the current and future state of the economy and of their own finances. It provides insight on the direction of the economy, because a change in the level of this indicator is associated with a similar change in consumer spending. As such, it is a key reference for financial markets in gauging the near future. A specific characteristic of consumer confidence is that it is already an opinion variable, resulting from consumer surveys conducted by the Conference Board. Investigating how experts behave in predicting consumers' perceptions is challenging in that it may either lead experts to make performant forecasts because they know consumers' beliefs as they share them (Townsend, 1983) or create increased heterogeneity due to a lack of salient common information, at least during periods of uncertainty. Apart from being among the variables most scrutinized by analysts, these indicators were also chosen to obtain the largest number of respondents and the longest uninterrupted prediction samples. Our empirical analysis covers the overall period June 1998 to August 2017, which encompasses all the individual prediction samples of our experts chosen. The selection of our panel of forecasters has been conditioned upon two requirements: (i) the forecast officer representing a given company has not changed for as long a period as possible; ${ }^{7}$ (ii) experts' individual sample periods overlap as durably as possible. The first requirement implies that our responses have no sampling bias. The second one allows reaching the longest possible common period to all respondents although the panel is unbalanced. ${ }^{8}$ By crossing these rules with the choice of our three indicators, we end up with a selection of 18 respondents. ${ }^{9}$ Although the analysts consulted by Bloomberg represent major investment banks, economic research organizations and academic institutions, only the former two categories met our requirement of a widest possible panel of data. Figures in Appendix A display the sample lengths of predictions provided by our experts to each macroeconomic indicator. Table 1 displays the average values of the forecast errors $a_{t}-E_{t-1}^{i} a_{t}$, where $a_{t}$ and $E_{t-1}^{i} a_{t}$ represent the announcement and its past forecast by agent $i$, respectively. In order to test whether the mean forecast error (MFE) is significantly different from zero, we regress the forecast error on a constant term using the Newey West methodology to account for the significant autocorrelation in residuals. The signs of the MFE are found to be systematically negative for $72 \%$ (13/18) of the respondents to the unemployment rate and positive for half $(9 / 18)$ of the respondents to new home sales, indicating that these agents expected in average a worsening in the employment situation and a shrink in new home sales. This suggests a pessimistic view of

\footnotetext{
${ }^{7}$ The very detailed information associated with the disaggregated surveys provided by Bloomberg makes it possible to follow the career of forecasters through several companies and select those who were not involved in institutional mobility for long sample periods.

${ }^{8}$ However, in order to keep the sample homogeneous, an exception was made for Nomura Securities (individual \# 14) who provided smaller series of answers in predicting the consumer confidence index. Test results are thus not provided for the case of this respondent to this variable (see Tables 1 to 4 ).

${ }^{9}$ These are Briefing.com, Deutsche Bank Securities, Credit Suisse, Morgan Stanley, Citi, CIBC World Markets, PNC Bank, Daiwa Securities America, Wrightson ICAP, IDEAglobal, BMO Capital Markets, BofA Merrill Lynch Research, High Frequency Economics, Nomura Securities Intl., First Trust Advisors, Goldman Sachs, Maria Fiorini Ramirez, and IHS Global Insight. These firms will be numbered in this order from 1 to 18 where appropriate.
} 
most of Bloomberg experts regarding the upcoming values of these two indicators. This pessimism was possibly sustained by the instability surrounding major shocks, such as the US 2001 recession and the 2007-2009 financial crisis, which are included in almost all the individual sample periods.

$<$ Insert Table $1>$

\section{Empirical analysis}

\subsection{Testing for the rationality and homogeneity of expectations}

We first check whether the widespread evidence on the rejection of the rational expectations hypothesis (REH) in the survey-based empirical literature on inflation and asset price expectations is still valid for macroeconomic indicators' individual forecasts. Testing for the REH requires performing unbiasedness and orthogonality test unless the null of unbiasedness is rejected, in which case we conclude that expectations are not rational. Let $a_{t}=\left\{h_{t}, s_{t}, u_{t}\right\}$ be the generic notation of the logarithm for new home sales $\left(h_{t}\right)$ the logarithm of the consumer confidence index $\left(s_{t}\right)$ and the unemployment rate $\left(u_{t}\right)$. Our unbiasedness test equation is $E_{t}^{i} a_{t+1}-a_{t}=\alpha_{i}+\beta_{i}\left(a_{t+1}-a_{t}\right)+\nu_{i, t+1}, i=1, . ., 18$, where $E_{t}^{i}$ is the expectation operator for forecaster $i$ conditional on information available at time $t .{ }^{10}$ Although not indicated, the parameters are variable-specific. The null of unbiasedness requires that the condition $\alpha_{i}=0, \beta_{i}=1$ be jointly satisfied and $\nu_{i, t+1}$ is white noise. We run the test separately for each forecaster and each macroeconomic indicator (i.e., 54 forecasts) using ordinary least squares (OLS) with Newey-West autocorrelation and heteroskedasticity-consistent standard errors. The regression results are reported in Table 2. Regarding the Wald tests, the null is strongly rejected in each case at all levels. These results underpin the outcomes from our analysis of forecast errors (Table 1). Note, however, that unbiasedness tests are more consistent than tests based on forecast errors as the latter introduces a constraint on a parameter.

$$
<\text { Insert Table } 2>
$$

To check for the presence of heterogeneity, we rely on Ito's (1990) approach. This test amounts to regressing the difference between the expert's forecast $E_{t}^{i} a_{t+1}$ and the market cross-section average forecast $E_{t}^{M} a_{t+1}$ on a constant term. If the latter parameter is significant, the agent's behavior is heterogeneous, as their forecast departs from that of the market. Otherwise, individual expectations collapse to that of the consensus because of homogeneous expectation formation by all forecasters. ${ }^{11}$ As seen from Table 2, unemploy-

\footnotetext{
${ }^{10}$ We choose this specification instead of the reverse equation linking the ex-post change in the observed value to the expected change because such an equation could present an endogenous regressor problem leading to inconsistent estimates.

${ }^{11}$ In its simplest version, Ito's (1990) test compares an agent $i$ 's expectation based on a public information component $f\left(I_{t}\right)$ and a private information component $g_{i}$, such that $E_{t}^{i} a_{t+1}=f\left(I_{t}\right)+g_{i}+\varepsilon_{i t}$, to the market average expectation defined as $E_{t}^{M} a_{t+1}=f\left(I_{t}\right)+g_{M}+\varepsilon_{M t}$, where $g_{M}$ is the average of the $g_{i}$ 's. Subtracting the latter from the former, we obtain the described test equation. If agent's private information is equal to the average private information (the intercept equals zero), nothing makes agent's expectation different from the market expectation and the null of homogeneity fails to be rejected.
} 
ment rate generates a number of heterogeneous forecasts for $55.5 \%$ of our respondents. One possible reason is that because the unemployment rate is the first indicator of economic activity released in the month, it is more difficult to predict ex-ante. As for new home sales, we find heterogeneity for half our panel of forecasters, possibly due to events such as the repeated sudden upsurges in different indices of homebuilders and mortgage companies in the early 2000's or investors' contrasting beliefs about the timing of the housing bubble crash at the dawn of the subprime crisis. Concerning the consumer confidence index, the null of homogeneity is rejected for only $11.8 \%$ of the panel. This suggests that to predict the opinion of households about the state and the near future of the economy, most analysts use a common set of determinants (although different from the one of the consumers since the REH is rejected). Overall, we can state that expectations of our set of macroeconomic indicators are moderately - but not negligibly - heterogeneous across our panel of respondents.

\subsection{Estimation of the individual flexible forecast models}

To test model (5), the only unknown variable we need to specify is the target value $\bar{a}_{t}$ appearing in the regressive component (2). Let $a_{t}=\bar{a}_{t}+\xi_{t}^{a}$, where $a_{t}=\left\{h_{t}, s_{t}, u_{t}\right\}$ and $\xi_{t}^{a}$ is assumed to be $I(0)$. For each macroeconomic indicator $a_{t}$ we specify the fundamentals driving the target value $\bar{a}_{t}$ and estimate the empirical model using the Newey-West autocorrelation and heteroskedasticity consistent covariance matrix estimator. Appendix B presents the three empirical models and the regression results. For $\bar{a}_{t}$ to be seen as a longrun fundamental value, variables in $\bar{a}_{t}$ must be cointegrated. We then perform unit root tests for residuals and assess the residual-based asymptotically critical values following MacKinnon (2001). We find that the three residuals $\xi_{t}^{a}$ are stationary at the $5 \%$ level, we can thus admit the variables $\bar{a}_{t}$, given by the deterministic parts of each regression model, as the target of the macroeconomic indicator in question. To account for time-flexibility in expectation formation, Bai and Perron's (BP; 1998, 2003) methodology with endogenous breakpoints. ${ }^{12}$ The model to be estimated becomes :

$$
E_{t}^{i} a_{t+1}-a_{t}=\sum_{j=1}^{m^{i}+1} \theta_{j}^{i^{\prime}} Z_{t}^{i} \mathbb{1}_{t \in I_{j}^{i}}+\varepsilon_{t}^{i}
$$

where $Z_{t}^{i}=\left(1, \mathrm{MA}_{j}^{i}\left(a_{t-j}-a_{t-j-1}\right), E_{t-1}^{i} a_{t}-a_{t}, \bar{a}_{t}-a_{t}, \mathrm{MA}_{j}^{i}\left(E_{t-j}^{M} a_{t-j+1}-E_{t-j}^{i} a_{t-j+1}\right)\right)^{\prime}$ $\theta_{j}^{i}=\left(\theta_{0, j}^{i}, \theta_{1, j}^{i}, \theta_{2, j}^{i}, \theta_{3, j}^{i}, \theta_{4, j}^{i}\right)^{\prime}, m^{i}$ is the unknown number of breaks specific to agent $i$, determined when the null of $m^{i}$ breaks is not rejected against $m^{i}+1$ breaks using a sequential F-test procedure. $I_{j}^{i}\left(j=1, \ldots, m^{i}+1\right)$ is the segment between break dates $t_{j-1}^{i}$ and $t_{j}^{i}$ and $\mathbb{1}_{t \in I_{j}^{i}}$ an indicator function such that $\mathbb{1}_{t \in I_{j}^{i}}=1$ if $t_{j-1}^{i}<t<t_{j}^{i}$ and 0

\footnotetext{
${ }^{12}$ It is worth emphasizing that estimating each agent's model with endogenous structural changes in parameters makes more sense than imposing exogenously break dates corresponding to major crises in the form of a Chow instability test. This is because all agents do not necessarily respond to a given economic shock at the same time, individual reaction times may differ between the ones who anticipate the event and those who adjust with delay. In this case, setting a break date arbitrarily can lead to inconsistent estimates.
} 
elsewhere $\left(t_{0}^{i}=1\right.$ and $\left.t_{m^{i}+1}^{i}=T\right)$. An estimated break date $\widehat{t_{j}^{i}}$ is obtained as a solution of $\arg \min _{\tau_{1} \leq t_{j}^{i} \leq \tau_{2}} S S R\left(t_{j}^{i}\right)$, where $S S R$ is the sum of squared residuals over the expert's sample, $\tau_{1}$ and $\tau_{2}$ are the first and last observations of the sample (adjusted for the trimming period) in the case of the first break search and the first and last observations of a sub-sample otherwise. If two consecutive break dates were found to be separated by a segment size of less than 30 monthly observations, we re-estimated model (6) by imposing the previous number of breaks so as to obtain segments long enough to ensure the validity of the parameter distributions. Only one such case occurred out of $18 \times 3=54$ estimations. When the OLS residuals from the BP method were found to be autocorrelated and/or heteroskedastic, the $F$-test statistic inherent in the sup $F$ test used to check for the presence of $m+1$ breaks against the null of $m$ breaks have been adjusted for the HAC consistent matrix of covariance, following Bai and Perron (2003). ${ }^{13}$ Consequently, the number and the location of the estimated breakpoints are such that autocorrelation and heteroskedasticity are eliminated. Table 3 provides the estimation results of our flexible forecast model for our 18 forecasters (to save space, the estimated models are summarized by the initials of the significant components; full results are available upon request).

\section{$<$ Insert Table $3>$}

Results suggest a high degree of instability in both coefficients and the functional form of the forecasting models. This flexibility in the forecasting behavior arises for both the unemployment rate and new home sales and to a lesser extent for the consumer confidence index. Overall, we can observe that analysts combine different rules whose weights change over sub-periods, which implies substantial time-variation in behavioral heterogeneity. ${ }^{14}$ The market for which forecasters have proven to be the most flexible over time in terms of their expectation behavior is the labor market. Fifteen out of 18 forecasters (i.e., $83 \%$ of the panel) have indeed repeatedly adjusted - from one up to four times depending on experts - the coefficients of their unemployment rate forecast model or changed its components. Such adjustments in the unemployment rate expectation process reflects a continuous search for accuracy in predicting this indicator, renowned for its link with all major real and financial sectors (bond and equity markets, production and income, interest rates) and therefore for its ability to reflect the current state of the economy as well as for its role in the conduct of monetary policy (Mishkin, 2009). Changes in the formation of new home sales expectations occur for the two-thirds of our forecasters especially during 2009-2010, when the housing market showed significant signs of recovery. Results also show that flexibility (changes in the model over time) arises with substantial inertia; when a mixed model is chosen, at least one of its components persists over two or more subsequent sub-periods. This indicates that, rather than abruptly switching from one belief to another in the forecast generating process, agents ensure mental continuity in

\footnotetext{
${ }^{13}$ Note that autocorrelation and heteroskedasticity in residuals may also arise if a structural change is omitted when in fact it has occurred. Because the number of breaks for each forecaster was determined endogenously and without restriction, this risk was excluded.

${ }^{14}$ This is in line with Capistran and Timmermann (2009) who, using survey data on inflation expectations, show that heterogeneity of professional forecasters varies systemically over time.
} 
forming their judgments. We find that the adaptive and extrapolative rules are the most pervasive strategies as they are maintained over two or more consecutive sub-periods in $70 \%$ of cases. The intuition of the prevalence of these two rules is straightforward: they are both backward looking strategies based on almost costless information - i.e., past observed values and past individual forecasts - which make them the building blocks of any mixed model chosen. This helps explain the proportion of homogeneous expectations regarding Ito's (1990) tests (section 4.1). Menkhoff and Taylor (2007, p.940) asked directly analysts in FX markets which forecasting method they use and outlined as a stylized fact that "almost all professionals use technical analysis as a tool in decision making at least at some degree." The relative inertia of the extrapolative behavior, which proxies technical analysis, shows the validity of this statement in the case of the real sector. We also find that most agents typically use complex forecast models for all indicators; in $41 \%$ of cases, forecasters combine at least three forecasting rules and choose in $21 \%$ of cases the four-component-model alone. Combined or not with other rules, the adaptive behavior appears throughout the sample period in $89 \%$ of the cases, the extrapolative component in $68 \%$, the regressive rule in $55 \%$ and the interactive process in $54 \%$. These non-zero rates suggest that learning from errors and interacting with the consensus are relevant behavior to be accounted for beyond the traditional chartist-fundamentalist model. ${ }^{15}$

From all the 58 cases of changes in expectation formation irrespective of our forecasters and variables, changes overwhelmingly seem to appear during periods of financial turmoil; 42 of them (72\%) occurred during the global financial crisis (2007-2010), with 23 changes in 2009 alone, a year of spectacular drops in value on the Standard \& Poor's 500 (JanuaryFebruary) and the Dow Jones Industrial Average (March), followed by the World Bank's projection that in 2009, global production would decline by $2.9 \%$ for the first time since World War II. Five cases (9\%) are located around the time of dot-com crash (2000-2002), among which two changes, dated in November and December 2001, may alternatively be attributed to the September 11 terrorist attacks. Also, the invasion of Iraq by the US-led coalition on March 2003 seems to have triggered five cases of changes (9\%) in our experts' forecast strategies. Only six changes $(10 \%)$ are likely to be due to other unidentified events or to idiosyncratic effects. Overall, these outcomes show that changes in forecasters' limited information-based models are produced mainly by common economic and financial shocks, although forecasters do not react to these shocks simultaneously; some of them anticipate the crises, others revise their strategies at the beginning of the event or with some delay.

In particular, it is meaningful to examine in which direction forecasters modify their behavior in the aftermath of economic shocks. Results show that the extrapolative-adaptiveinteractive process and the full model were prompted by agents the most frequently at different dates of the global financial crisis (2007-2009). This shows, first, that in crisis periods, agents tend to rely on complex forecast models. In such periods, they possibly

\footnotetext{
${ }^{15}$ We are grateful to Nicolas Sopel, expert global macro forecaster at the RHB Research Institute, for providing useful information from their own experience and for confirming the practical relevance of the four forecast methods described in our analysis.
} 
face higher information costs because uncertainty requires larger amounts of information, but they bear these costs because they have higher aversion to making forecast errors. This result is in line with Baker et al. (2019) who show that following an unexpected (natural disaster) shock, the rise in uncertainty leads attentive agents - who regularly monitor new information - to increase the amount of their private information and inattentive agents - who infrequently collect information - to update their information set. Second, we find strong evidence that episodes of instability lead agents to become less chartist and more fundamentalist. Of the 14 experts who experienced a structural break at 2009 in predicting the unemployment rate, 10 distrusted recent trends as relevant predictors by lowering their extrapolative (bandwagon) view, while 10 reinforced their fundamentalist profile by relying on a less divergent dynamic (i.e., declining raise in the unemployment rate) in most of the cases or on a mean-reverting pattern (convergence to the natural rate) otherwise. Overall, these changes suggest that forecasters have stabilizing beliefs about post crisis trends. Concerning the interactive component that is very present in analysts' unemployment rate forecast models during the financial crisis, we found that its impact is significantly positive over the period, suggesting that experts generally consider the strategy of the majority (i.e., the consensus) a reliable reference under uncertainty. However, these impacts decreased for $71 \%$ of the cases after the 2009 individual breakdates compared to before them, indicating that most agents mimic the market to a lesser extent because of its inability to predict the crisis. Our results show that the interactive rule is employed much less to predict unemployment rate than the other indicators after the financial crisis.

\subsection{How good are forecasters?}

In this section, we classify our respondents according to their institutional affiliations, which are research institutes or investment banks, and we compute for each group different measures of forecast accuracy: the Root Mean Squared Error (RMSE), the Mean Absolute Error (MAE), the Mean Absolute Percentage Error (MAPE) and the second Theil Inequality Coefficient (Theil) (Table 4, Panel A). The three former measures are designed to evaluate the distance between the past individual forecasts and the observed values. The Theil's Coefficient confirms that all experts do better than naïve forecasts, except the less performant forecasters of NHS and UR. To check whether the differences between more accurate and less accurate forecasts regarding the RMSE and MAE criteria are significant and, if yes, to identify the smallest significant difference, we carry out Diebold-Mariano (DM) tests with alternative loss functions based on the mean squared prediction error (MSE) and the mean absolute prediction error (MAE). Panel B (Table 4) displays the corresponding DM statistics for the smallest significant differences in accuracy, named "H1-region bounds", such that for larger differences the null of equality is systematically rejected (H1 accepted) at possibly higher levels of significance, while it fails to be rejected for even smaller differences. In each institutional category and for each indicator, the best forecasters are found to be significantly more accurate than the less performant ones at the $5 \%$ or $10 \%$ level and according to at least one of the loss 
function(s).

$$
<\text { Insert Table } 4>
$$

Additional DM test results on institutional differences (not reported) have shown that none of the professional categories make significantly better forecasts than the other concerning UR and CCI, whether the comparison criterion is the best performances in both groups, the group averages and the group medians. In the case of NHS, however, research institutions beat the banks on average at the 10\% level and according to MSE loss function. Another interesting outcome consists in linking forecasters' performance to their anticipative behavior analyzed in section 4.2 in order to identify which forecasting model allows for the highest forecast accuracy. Bringing together the findings in Tables 3 and 4 , it seems that forecasters who provide the best anticipative performance are those who have the ability to combine different relevant rules and to revise their model over time. This can be summarized as the principle "the winners are those who adapt best," which supposes that performant agents continuously seek the optimal trade-off between the appropriate types and amounts of information, given their cost/aversion ratio. Of course, this approach does not enable them to make rational expectations, but permits them to achieve the highest forecast accuracy under the assumed conditions of bounded rationality. 


\section{Conclusion}

The goal of this paper is to investigate individual forecasters' dynamic behavior in predicting various macroeconomic indicators from June 1998 to August 2017. We show that analysts use an extrapolative-regressive-adaptive-interactive model, of which they revise the component weights over time. To estimate this model, we use Bloomberg's disaggregated monthly surveys of experts' one month horizon forecasts on three major macroeconomic indicators: new home sales, unemployment, and consumer sentiment index.

We first verify that individual expectations are moderately heterogeneous but not rational, and hence confirm with our data two findings that are well documented in the empirical literature using survey data. The estimation of our flexible mixed expectations model using Bai and Perron's (1998, 2003) method with endogenous breaks leads to five main findings: (i) Beyond the standard extrapolative, regressive, and adaptive forecast processes, interacting with the consensus appears to be a complementary and important strategy that needs to be taken into account when using individual series. (ii) Both the structural coefficients and the functional forms of the mixed forecast models are prone to change over time. This flexibility in forecasting behavior is the source of the time-varying heterogeneity in analysts' expectations and occurs with a core of substantially stable components: the chartist activity and adaptive behavior. The labor market is where forecasters have proven to be the most flexible over time. (iii) Changes in expectation formation are triggered mostly by economic or financial shocks. Forecast models based on the widest variety of information were mostly used after the global financial crisis. (iv) Periods of economic downturn lead agents to become less chartist in the labor market. At the same time they become more fundamentalist in that they believe to a decreasing raise in the rate of unemployment due to the forces of market fundamentals. (v) Forecasters whose models combine different relevant rules and display high temporal flexibility provide the most accurate forecasts.

Overall, these findings imply that professional experts influence investors' beliefs through their biased (or information cost-dependent) and destabilizing (bandwagon) expectations which, in turn, affect real markets. To stabilize these markets, authorities should encourage fundamentalist behavior with a broader transparency policy, leading to an increased readability of their actions. 


\section{Appendix A}

$$
<\text { Insert Figure }>
$$

\section{Appendix B}

We assume that new home sales (NHS) depend on a housing investment effect represented by an increasing real estate price index, a real income effect and the mortgage market conditions:

$$
\begin{gathered}
h_{t}=\underset{(12.62)}{-53.5}+\underset{(0.28)}{3.20} p_{t}+\underset{(1.47)}{5.20} y_{t}-\underset{(0.04)}{0.44} R 30_{t}^{H P}+\underset{(0.05)}{0.74 T^{2}}-\underset{(0.25)}{4.54 T}+\widehat{\xi}_{t}^{h} \\
R^{2}=0.95 \quad A D F=-7.66 \quad A C V(5 \%)=-4.72
\end{gathered}
$$

where $h_{t}$ is the $\log$ of the NHS index, $p_{t}$ the $\log$ of the FHFA house price index, $y_{t}$ the $\log$ of the real GDP, $R 30_{t}^{H P}$ the Hodrick-Prescott filtered 30-year fixed mortgage rate and where the trend polynomial proxies for population growth. The Consumer Confidence Index (CCI) reflects consumer opinion about the overall health of the economy, of which key indicators are the growth rate trend and unemployment to gauge economic activity and the VIX index, a widely agreed barometer of financial market volatility.

$$
\begin{gathered}
s_{t}=\underset{(0.07)}{6.07}-\underset{(0.03)}{0.92} u_{t}+\underset{(0.06)}{0.60}\left[100 \mathrm{MA}_{6}\left(\Delta y_{t}\right)\right]-\underset{(0.001)}{0.005 V I X_{t}}+\widehat{\xi}_{t}^{s} \\
R^{2}=0.86 \quad A D F=-6.12 \quad A C V(5 \%)=-3.33
\end{gathered}
$$

where $s_{t}$ is the $\log$ of the CCI, $100 \mathrm{MA}_{6}\left(\Delta y_{t}\right)$ the moving average of order 6 of the log of the real GDP growth rate, $u_{t}$ the $\log$ of the unemployment rate and $V I X_{t}$ the Chicago Board Options Exchange volatility index implied by S\&P 500 option prices. To model the unemployment rate $u_{t}$, we rely upon Okun's law, which states that the rate at which production capacity is underutilized depends on how much actual unemployment exceeds the natural rate of unemployment. We thus derive and fit the following equation:

$$
\begin{gathered}
u_{t}=\bar{u}_{t}+\underset{(0.02)}{0.67}\left[100 \frac{\left.y_{t}^{H P}-y_{t}\right)}{y_{t}^{H P}}\right]+\widehat{\xi}_{t}^{u} \\
R^{2}=0.85 \quad A D F=-2.37 \quad A C V(5 \%)=1.94
\end{gathered}
$$

where $\bar{u}_{t}$ is the short term NAIRU (non-accelerating inflation rate of unemployment) and $y_{t}^{H P}$ the Hodrick-Prescott filtered potential GNP. 


\section{References}

Bai, J. and Perron, P. (1998). Estimating and testing linear models with multiple structural changes. Econometrica, 66(1):47-78.

Bai, J. and Perron, P. (2003). Computation and analysis of multiple structural change models. Journal of Applied Econometrics, 18(1):1-22.

Baker, S. R., McElroy, T. S., and Sheng, X. S. (2019). Expectation formation following large unexpected shocks. The Review of Economics and Statistics, 0(ja):1-45.

Branch, W. A. (2004). The theory of rationally heterogeneous expectations: evidence from survey data on inflation expectations. The Economic Journal, 114(497):592-621.

Brock, W. and Hommes, C. (1997). A rational route to randomness. Econometrica, 65(5):1059-1096.

Brock, W. and Hommes, C. (1998). Heterogeneous beliefs and routes to chaos in a simple asset pricing model. Journal of Economic Dynamics and Control, 22(8-9):1235-1274.

Canova, F. (2009). Multiple filtering devices for the estimation of cyclical dsge models. SSRN Electronic Journal.

Capistran, C. and Timmermann, A. (2009). Disagreement and biases in inflation expectations. Journal of Money, Credit and Banking, 41(2-3):365-396.

Cogley, T. and Sargent, T. J. (2005). Drift and Volatilities: Monetary Policies and Outcomes in the Post WWII U.S. Review of Economic Dynamics, 8(2):262-302.

De Grauwe, P. and Grimaldi, M. (2006). Exchange rate puzzles: A tale of switching attractors. European Economic Review, 50(1):1-33.

Feige, E. and Pearce, D. (1976). Economically rational expectations: Are innovations in the rate of inflation independent of innovations in measures of monetary and fiscal policy? Journal of Political Economy, 84(3):499-522.

Fernald, J. G. (2007). Trend breaks, long-run restrictions, and contractionary technology improvements. Journal of Monetary Economics, 54(8):2467-2485.

Flieth, B. and Foster, J. (2002). Interactive expectations. Journal of Evolutionary Economics, 12(4):375-395.

Gabaix, X. (2014). A sparsity-based model of bounded rationality. The Quarterly Journal of Economics, 129(4):1661-1710.

Haltiwanger, J. and Waldman, M. (1985). Rational expectations and the limits of rationality: An analysis of heterogeneity. American Economic Review, 75(3):326-40.

Haltiwanger, J. and Waldman, M. (1989). Limited rationality and strategic complements: The implications for macroeconomics. The Quarterly Journal of Economics, 104(3):463. 
Hess, D. and Orbe, S. (2013). Irrationality or Efficiency of Macroeconomic Survey Forecasts? Implications from the Anchoring Bias Test. Review of Finance, 17(6):2097-2131.

Hommes, C. (2006). Heterogeneous agent models in economics and finance. In Tesfatsion, L. and Judd, K. L., editors, Handbook of Computational Economics, volume 2, chapter 23, pages 1109-1186. Elsevier, 1 edition.

Inoue, A. and Rossi, B. (2011). Identifying the sources of instabilities in macroeconomic fluctuations. Review of Economics and Statistics, 93(4):1186-1204.

Ireland, P. N. (2001). Sticky-price models of the business cycle: Specification and stability. Journal of Monetary Economics, 47(1):3-18.

Ito, T. (1990). Foreign exchange rate expectations: Micro survey data. American Economic Review, 80(3):434-49.

Jongen, R., Verschoor, W., Wolff, C., and Zwinkels, R. (2012). Explaining dispersion in foreign exchange expectations: A heterogeneous agent approach. Journal of Economic Dynamics and Control, 36.

Kirman, A. (2006). Heterogeneity in economics. Journal of Economic Interaction and Coordination, 1(1):89-117.

MacKinnon, J. G. (2001). Computing Numerical Distribution Functions in Econometrics. Working Papers 1037, Queen's University, Department of Economics.

Mankiw, G. and Reis, R. (2002). Sticky information versus sticky prices: a proposal to replace the new keynesian phillips curve. The Quarterly Journal of Economics, 117(4):1295-1328.

Menkhoff, L. and Taylor, M. P. (2007). The obstinate passion of foreign exchange professionals: Technical analysis. Journal of Economic Literature, 45(4):936-972.

Mishkin, F. S. (2009). Is monetary policy effective during financial crises? American Economic Review, 99(2):573-77.

Pesaran, M. H., Smith, R. P., and Yeo, J. S. (1985). Testing for structural stability and predictive failure: A review. The Manchester School, 53(3):280-295.

Sims, C. A. (2003). Implications of rational inattention. Journal of Monetary Economics, 50(3):665-690.

Sims, C. A. and Zha, T. (2006). Were there regime switches in u.s. monetary policy? American Economic Review, 96(1):54-81.

Spronk, Richard, W. F. V. and Zwinkels, R. C. (2013). Carry trade and foreign exchange rate puzzles. European Economic Review, 60:17-31. 
ter Ellen, S., Verschoor, W., and Zwinkels, R. (2013). Dynamic expectation formation in the foreign exchange market. Journal of International Money and Finance, 37(C):75-97.

Townsend, R. M. (1983). Forecasting the forecasts of others. Journal of Political Economy, 91(4):546-588.

Tversky, A. and Kahneman, D. (1974). Judgment under uncertainty: Heuristics and biases. Science, 185(4157):1124-1131.

Woodford, M. (2002). Imperfect common knowledge and the effects of monetary policy. In Knowledge, Information and Expectations in Modern Macroeconomics: In Honor of Edmund S. Phelps, P. Aghion, R. Frydman, J. Stiglitz, and M. Woodford (Eds), Princeton: Princeton university press. 